\title{
Recommendations from the Brazilian society of rheumatology for the diagnosis of Sjögren's syndrome (Part I): glandular manifestations (systematic review)
}

Virginia Fernandes Moça Trevisani ${ }^{1,2^{*}}$ D, Sandra Gofinet Pasoto ${ }^{3}$, Marilena Leal Mesquita Silvestre Fernandes ${ }^{4}$, Maria Lúcia Lemos Lopes ${ }^{5}$, Sonia Cristina de Magalhães Souza Fialho ${ }^{6}$, Aysa César Pinheiro ${ }^{7}$, Laura Caldas dos Santos ${ }^{8}$, Simone Appenzeller ${ }^{9}$, Tania Fidelix ${ }^{8}$, Sandra Lúcia Euzébio Ribeiro ${ }^{10}$, Danielle Christinne Soares Egypto de Brito ${ }^{11}$, Tatiana Libório ${ }^{10}$, Maria Carmen Lopes Ferreira Silva Santos ${ }^{12}$, Leandro Tanure $^{13}$, Juliana D Agostino Gennari ${ }^{14}$, Vinicius Tassoni Civile ${ }^{1}$, Ana Carolina Pereira Nunes Pinto ${ }^{1}$, Fabíola Reis Oliveira ${ }^{15}$, Jaqueline Martins de Sousa ${ }^{8}$, Samira Tatiyama Miyamoto ${ }^{16}$ and Valeria Valim ${ }^{17}$

\begin{abstract}
Background: Primary Sjögren's syndrome (pSS) is a systemic immune-mediated disease whose main characteristic is exocrine gland inflammation and, subsequent reduction in tear and saliva production. A delayed diagnosis is common due to the nonspecific clinical manifestations of disease. The aim of the present study was to develop recommendations for the diagnosis of glandular manifestations of pSS based on evidence and expert opinion.

Main body of the abstract: We conducted a systematic literature review to retrieve the best evidence available on the accuracy of diagnostic tests for pSS. We also held two in-person meetings with experts (rheumatologists, pathologists, ophthalmologists and dentists) to establish their level of agreement using the Delphi method. Ultimately, we generated 18 recommendations that aim to facilitate the diagnosis of the glandular manifestations of pSS.

Conclusion: The diagnosis of glandular manifestations of pSS is complex and multidisciplinary. It requires specific knowledge in the field of ophthalmology, immunology, pathology and imaging, making it compulsory for the rheumatologist to work with professionals from these different areas in order to improve accuracy and early diagnosis. Glandular dysfunction tests, ANA, RF, Anti-Ro, protein electrophoresis, urinalysis, blood count, C-Reactive protein, complement, testing for syphilis and viruses (HCV, HIV) and SGUS should be investigated when dryness or systemic manifestation are present. Minor salivary gland biopsy is recommended for all anti-Ro negative or incomplete criteria cases.
\end{abstract}

Keywords: Sjogren's syndrome, Xerostomia, Xerophthalmia, Salivary gland diseases, Lacrimal apparatus diseases, Diagnosis, Practice guideline

\footnotetext{
*Correspondence: vmoca@uol.com.br

'Disciplina de Medicina de Urgência e Medicina Baseada em Evidências,

Escola Paulista de Medicina-Universidade Federal de São Paulo

(EPM-UNIFESP), Rua Botucatu 740 Vila Clementino, São Paulo, SP CEP:

04023-062, Brazil

2Disciplina de Reumatologia, Universidade de Santo Amaro, Rua Enéas

Siqueira Neto, Jardim das Embuias, São Paulo, SP CEP: 04829-300, Brazil

Full list of author information is available at the end of the article
}

(c) The Author(s). 2019 Open Access This article is distributed under the terms of the Creative Commons Attribution 4.0 International License (http://creativecommons.org/licenses/by/4.0/), which permits unrestricted use, distribution, and reproduction in any medium, provided you give appropriate credit to the original author(s) and the source, provide a link to the Creative Commons license, and indicate if changes were made. The Creative Commons Public Domain Dedication waiver (http://creativecommons.org/publicdomain/zero/1.0/) applies to the data made available in this article, unless otherwise stated. 


\section{Background}

Sjögren's syndrome (SS) is a systemic immune-mediated disease that affects the exocrine glands, particularly the salivary and lacrimal glands, with a subsequent reduction in saliva and tear production. SS is characterized by extensive lymphoplasmacytic infiltrates that cause the destruction and loss of the secretory function of glands, resulting in symptoms such as dry mouth and dry eyes [1].

SS may occur alone, a condition known as primary SS (pSS), or in combination with other immune-mediated rheumatic diseases, such as rheumatoid arthritis (RA), systemic lupus erythematosus (SLE) and systemic sclerosis (SSc) [1], when it is called associated or secondary SS (sSS).

A diagnosis of pSS is established, on average, 6 to 10 years after the onset of the disease because of the nonspecific nature of its clinical manifestations. Three SS classification criteria were formulated over the past two decades, and all of them are used in clinical practice [2-4].

The objectives of the present study were to conduct a systematic review according to recommendations of the Cochrane Collaboration (Higgins, Green [5)], and retrieve the best evidence available on the accuracy of diagnostic tests used for patients with glandular manifestations of pSS and to formulate recommendations to aid in the diagnosis of pSS and of its glandular involvement.

\section{Methods}

A systematic literature review of the items included in the 2002, 2010 and 2016 classification criteria was performed. A search strategy was designed for the electronic databases Cochrane Central Register of Controlled Trials, MEDLINE, Embase, LILACS and www.guidelines.gov (for guidelines). This search strategy was based on structured questions formulated according to the PICO method ("Patients," "Index test," "Comparator" tests relative to the index test and "Outcomes"). We applied filters for studies on diagnostic tests. The search was conducted without any language, date or other type of restrictions. We included studies that assessed the accuracy of any test of gland dysfunction in patients with SS. The outcomes considered were accuracy, sensitivity and specificity. The methodological quality of the studies was analyzed according to the Quality Assessment of Diagnostic Accuracy Studies-QUADAS-2 [6] (see Additional file 1). Agreement among experts was investigated using the Delphi method in in-person meetings that included rheumatologists, ophthalmologists, pathologists and dentists. We ultimately generated 18 recommendations addressing the diagnosis of glandular dysfunction, histopathological findings in minor salivary gland biopsy specimens and salivary glands ultrasound (SGUS).

\section{Recommendations}

1. Patients with sicca syndrome and/or characteristic systemic and/or serological manifestations should be assessed for Sjögren's syndrome. A rheumatologist should preferentially lead the investigation. No single diagnostic test enables a definitive diagnosis of SS.

2. In patients with gland dysfunction or other suspected manifestations, serological tests for hepatitis $C$, hepatitis B, and HIV, as well as the Venereal Disease Research Laboratory (VDRL) test, are recommended. According to the clinical condition of patients, lymphoma, previous radiotherapy, hyper-IgG4 syndrome, graft-versus-host disease, sarcoidosis and other connective tissue disorders should be considered when determining the differential diagnosis.

3. The 2016 ACR/EULAR SS classification criteria are used in clinical studies. Their high sensitivity and specificity might make them useful to guide investigations.

The criteria established by the American-European Consensus Group (AECG) in 2002 [2] are the most widely accepted and remained in force for a decade. However, over time, some assessment tests included in those criteria were replaced by other tests because of adverse effects or a lack of diagnostic sensitivity and specificity. In 2012 [3], following a National Institutes of Health (NIH)-sponsored observational study, the SICCA (Sjögren's International Collaborative Clinical Alliance) published new diagnostic criteria. However, these criteria were not universally accepted because they do not include tests assessing dry mouth. In 2016, the International Sjogren's Syndrome Criteria Working Group (ACR/EULAR) [4] formulated new criteria for pSS that are universally accepted and served as the basis for the present recommendations.

\section{Objective tests to establish gland involvement are indicated in all suspected cases, including in individuals with systemic manifestations and the absence of dry symptoms.}

The main oral complaint of patients with SS is dry mouth, also known as xerostomia. However, this condition is not exclusive to SS and sometimes is not correlated with objective measures of hyposalivation. A large NIH cohort was recruited to establish the value of dry mouth complaints to distinguish between patients with SS and other dry syndromes. Of 1303 participants, 74\% reported dry mouth, which was more frequent among the patients with SS (87.4\%). The utility of xerostomia as an indicator for the diagnosis of SS among high-risk patients had a sensitivity of $87.4 \%$ ( $95 \%$ confidence interval (CI): $84.8-89.8 \%$ ), a specificity of $41.7 \%$ (95\% CI: $37.7-$ 
$45.7 \%$ ), a positive predictive value (PPV) of $64 \%$ and negative predictive value (NPV) of 74\% [7].

Most patients with SS complain of dry symptoms, which therefore are the main clinical manifestations leading to a suspicion of SS. However, clinicians should remember that dissociation between symptoms and gland dysfunction might occur based on objective tests, and systemic manifestations might antecede glandular manifestations. For this reason, the new 2016 ACR/EULAR classification criteria recommend an investigation of all patients with suspected SS presenting with dry symptoms or systemic manifestations, including gland dysfunction tests [4].

\section{Sialometry should be performed using the} unstimulated whole saliva flow rate method, where all the saliva ( $0.1 \mathrm{~g}$ is equivalent to $0.1 \mathrm{ml}$ ) produced over 15 min is passively collected into a graduated tube or a container previously weighted on a highly precise scale. The cut-off point for normal saliva production is $0.1 \mathrm{ml} / \mathrm{min}$.

In addition to dry mouth and hyposalivation, many other conditions might impair the oral health and consequently the quality of life of patients, such as, dental caries, oral candidiasis, bacterial sialoadenitis, halitosis and oral ulcers. Hyposalivation might impair taste perception and thus reduce the pleasure of eating. These secondary manifestations are usually the first symptoms of disease and are present in approximately $50 \%$ of patients with pSS. Investigations of dry mouth range from primary methods, such as sialometry, to more complex imaging methods, such as contrast magnetic resonance imaging (MRI) [8].

Sialometry is the quantitative evaluation of xerostomia. The technique might target the whole saliva or the saliva produced by some particular salivary gland under stimulated or unstimulated conditions. Stimuli for saliva secretion collection may be gustatory ( $2 \%$ citric acid administered to the lateral margins of the tongue) or mechanical (chewing paraffin, silicon or unflavored chewing gum) [9]. The whole salivary flow (WSF) varies as a function of the time of year and time of day, environmental noise, relative humidity, environmental temperature and duration of fasting. The best standards should be adopted in the collection methods to ensure the reliability of the results $[8,9]$. The unstimulated WSF (UWSF) method is the most widely used method in clinical practice. After a 2-h fast, the patient is requested to sit in a quiet room and spit all the saliva produced over 15 min into a pre-weighed tube or container. On a highly precise scale, $1 \mathrm{~g}$ is equivalent to $1 \mathrm{ml}$; therefore, after subtracting the weight of the container, $0.1 \mathrm{~g}$ of saliva is equivalent to $0.1 \mathrm{ml}[9,10]$. Cut-off points are $0.1 \mathrm{ml} / \mathrm{min}$ for the UWSF and $0.5 \mathrm{ml} / \mathrm{min}$ for the stimulated WSF $[9,10]$. In 1993, Pennec et al. [10] compared the accuracy of UWSF and others techniques used to assess xerostomia, including sialography, scintigraphy and salivary gland biopsy, among 40 individuals with pSS, 16 patients with secondary SS (sSS), 16 patients with connective tissue diseases and 14 healthy subjects. For pSS, the UWSF test exhibited 68\% sensitivity, $81 \%$ specificity, a PPV of $90 \%$ and an NPV of $50 \%$ compared with sialography $(74,87,93$, and $41 \%$, respectively), scintigraphy $(75,75,90$, and $45 \%$, respectively) and salivary gland biopsy $(95,75,90$, and $14 \%$, respectively). A multicenter study with 693 patients was conducted in 1993 to test the diagnostic criteria that were eventually included in the 2002 classification [11], and determined cut-off points for the unstimulated and stimulated WSF and the corresponding sensitivity and specificity. An UWSF $<0.1 \mathrm{ml} / \mathrm{min}$ had sensitivity of $66.6 \%$ and specificity of $86.1 \%$ for the diagnosis of dry mouth. The corresponding values for the stimulated WSF were 64.7 and $60.1 \%$, respectively, but the difference was not significant $[11,12]$. The stimulated WSF is recommended for assessments in patients with an advanced disease [12]. The studies described in this section are summarized in Table 1.

\section{Sialography (radiosialography) should not be} performed to investigate dry mouth in patients with SS due to its adverse effects and inconsistent results in accuracy studies. When necessary, it should be replaced by magnetic resonance sialography.

Sialography consists of the radiographic examination of the major salivary glands using a contrast agent. A specialist should perform to ensure the access to the ducts specific to the salivary glands (Stensen and Wharton ducts) for a retrograde injection of the iodinated contrast agent. In patients with SS, the exam shows distorted and dilated ducts and an irregular distribution of the contrast material inside the glands. Rubin and Holt [13] developed a staging system for sialography in patients with SS comprising comprises five categories: no contrast retention (normal) or punctate, globular, cavity and destructive contrast retention in the salivary glands. Typical findings on sialography among patients with SS are duct dilatation or stenosis and leakage or punctate contrast retention (sialectasis). While sialography is mentioned as a diagnostic test for glandular abnormality in the 2002 AECG criteria, it is no longer included in the 2016 ACR/EULAR classification criteria $[3,4]$. This technique might yield false-positive and false-negative results, in addition to being associated with a higher rate of complications. Possible problems include the retention of the contrast agent in the diseased salivary glands, a failure to access the glandular ducts, painful gland swelling, infection and allergic reactions in 2 to $10 \%$ of patients $[14,15]$. Studies of the accuracy of sialography in diagnosing SS reported inconsistent results due to methodological problems that 
Table 1 Sialometry for the diagnosis of Sjögren's syndrome

\begin{tabular}{llllll}
\hline Author & N & Sensitivity (\%) & Specificity (\%) & PPV (\%) & NPV (\%) \\
\hline Pennec 1993 [10] & 86 & 68 & 81 & 90 & 50 \\
Vitali 1993 [11] & 378 & 66.5 & 86.1 & - & - \\
Billings 2016 [7] & 331 & 63.8 & 51.3 & 60.1 & 55.2 \\
\hline
\end{tabular}

PPV Positive predictive value, NPV Negative predictive value

are mainly related to the sample size and application of different diagnostic criteria. A meta-analysis published in 2014 including 6 studies with 987 patients revealed the non inferiority of ultrasound compared to sialography for the diagnosis of pSS [16-21]. The findings for the sensitivity and specificity of sialography are described in Table 2. Studies that were not included in this metaanalysis but are likely to provide additional relevant information are also shown in Table 2 [22, 23]. In a summary of the results from all these studies, the sensitivity of contrast sialography ranged from 72 to $92 \%$ and the specificity ranged from 70 to $100 \%$.

Magnetic resonance sialography was described by Lomas et al. [24] in 1996. While its accuracy is equivalent to conventional X-ray sialography, it is a safer technique. Other imaging methods, such as MRI, computed tomography, ultrasound and scintigraphy provide images of the gland parenchyma, but not of salivary ducts, and do not allow clinicians to monitor the progression of lesions. In contrast, magnetic resonance sialography allows clinicians to visualize the contrast between the intraductal fluid and the gland tissue. The main advantage of this technique compared with conventional X-ray sialography is that it avoids exposure to ionizing radiation, the use of cannulas and retrograde contrast injection. The present literature review retrieved five studies [25-29] that were used to determine the accuracy of this method. The results are described in Table 3; the sensitivity ranged from 69 to $100 \%$ and the specificity ranged from 71 to $100 \%$.

7. Although not included in the 2016 ACR/EULAR criteria, salivary gland scintigraphy is useful for functional evaluations. In patients with SS, scintigraphy identifies the delayed uptake, decreased concentration and/or delayed excretion of the tracer.

Scintigraphy with technetium pertechnetate (Tc) is a noninvasive method for evaluating gland function that is useful for diagnosing SS. This method does not require previous preparation. Patients are administered an intravenous injection of Tc, placed in front of the gamma camera and images are acquired before and after the stimulation of saliva secretion, usually with lemon juice. Images are acquired for up to $60 \mathrm{~min}$ after the Tc injection. While this method is included in the 2002 diagnostic criteria, it is not able to establish the cause of imaging abnormalities. The pattern observed in patients with SS might be the same as the patterns associated with chronic sialadenitis, drug effects or metabolic disorders. The protocols for interpreting findings are also not clearly defined. The only information available is that in patients with SS, scintigraphy shows a delayed uptake, decreased concentration and/or delayed excretion of the tracer. In a study with a large cohort of patients with SS that was conducted to investigate possible tracers that are able to correlate scores of scintigraphy abnormalities with disease activity, positive correlations were observed between the highest scores and systemic involvement and lymphoma [30]. According to Shall et al., based on the pattern of $99 \mathrm{mTc}$ pertechnetate uptake, concentration, and excretion by the major salivary glands, it is possible to classify scintigraphy findings into four classes, ranging from class 1 - normal findings (rapid uptake, progressive increase in the concentration and rapid excretion into the oral cavity within $10 \mathrm{~min}$ ) to class 4 - very severe involvement (delayed uptake and elimination of the radiotracer requiring longer than $60 \mathrm{~min}$ ) [31]. The present systematic literature

Table 2 Sialography for the diagnosis of Sjögren's syndrome

\begin{tabular}{llllll}
\hline Author & N & Sensitivity (\%) & Specificity (\%) & PPV (\%)/ NPV (\%) & Accuracy (\%) \\
\hline Obinata 2010 [16] & 73 & 83 & 94 & - & - \\
Poul 2008 [17] & 60 & 77 & 86 & - & - \\
Salaffi 2008 [18] & 156 & 72 & $84 / 56$ & - \\
Yonetsu 2002 [19] & 294 & 87 & 98 & - & 92 \\
Yoshiura 1997 [20] & 44 & 92 & 81 & $82 / 78$ & 90 \\
Takagi 2010 [21] & 360 & 78 & 82 & - & - \\
Vitali 1994 [22] & 134 & 78 & 100 & $67 / 93$ & 93 \\
Wouter 2002 [23] & 100 & 92 & 70 & & 90 \\
\hline
\end{tabular}

PPV Positive predictive value, NPV Negative predictive value 
Table 3 Magnetic resonance sialography for the diagnosis of SS

\begin{tabular}{lllllll}
\hline Author & N & Sensitivity (\%) & Specificity (\%) & PPV (\%) & NPV (\%) & Accuracy (\%) \\
\hline Niemelä 2004 [26] & 54 & 96 & - & - & - & - \\
Yu 2007 [27] & 25 & 92 & 71 & - & - & - \\
Ohbayashi 1998 [27] & 35 & 100 & 100 & 100 & 69 & - \\
Tonami 2001 [28] & 130 & 73 & 100 & - & - & 83 \\
Kojima 2017 [29] & 69 & 69 & 88 & -5 \\
\hline
\end{tabular}

PPV Positive predictive value, NPV Negative predictive value

identified studies that describe the accuracy of the method. The sensitivity ranged from 47 to $88 \%$ and specificity ranged from 50 to $89 \%$ (Table 4). Therefore, scintigraphy is considered a secondary method for the assessment of outcomes relative to other imaging techniques.

\section{Salivary gland ultrasound (SGUS) is useful for the} diagnosis of SS. Although it has not yet been included in diagnostic criteria, it should be included in clinical practice because it increases the diagnostic sensitivity and it shows adequate specificity.

SGUS is a noninvasive imaging method that can be performed at the bedside in patients with pSS. It is a useful tool for determining the diagnosis, prognosis and treatment of pSS. Some studies compared SGUS to minor salivary gland or parotid biopsy, sialography and scintigraphy of the major salivary glands [32-34]. The sensitivity of SGUS is comparable to sialography and scintigraphy, and its specificity is comparable to minor salivary gland biopsy $[21,34,35]$.

Although it has not yet been included in classification criteria, SGUS increases the sensitivity and accuracy of diagnosis [35, 36]. The addition of SGUS to the 2016 ACR/EULAR criteria increased the sensitivity from 87 to 92\% [37]. In another study with patients with rheumatic disorders, SGUS abnormalities were detected in $93 \%$ of the patients with pSS, $27.3 \%$ of patients with SS associated with another autoimmune disease, $50 \%$ of the patients with dry symptoms and $11 \%$ of the asymptomatic controls, with a sensitivity of $95.1 \%$, specificity of $90 \%$, PPV of $72 \%$ and NPV of $96 \%$ [38].

A systematic review of studies published from January 1988 through January 2013 analyzed the scoring systems used, type and number of salivary glands tested, study design and metric properties according to the Outcome Measures in Rheumatology (OMERACT) filter (truth, discrimination and feasibility). In patients suspected of having pSS, SGUS exhibited sensitivity of 45.8 to $91.6 \%$ and specificity of 73 to $98.1 \%$ [39]. However, a metaanalysis of studies published prior to June 2014 detected significant heterogeneity among studies regarding patient selection and flow, procedures, interpretation of SGUS findings and duration of tests [40].

The accuracy of SGUS for detecting pSS was investigated among patients for whom $\leq 5$ years had elapsed since the onset of symptoms [41]. The sensitivity was $66 \%$, the specificity was $98 \%$, the PPV was $97 \%$ and the NPV was $73 \%$ for the early diagnosis of pSS.

In the salivary glands, the recommendation is to use a modern, high-resolution US machine and linear transducer (6-15 MHz probes). Both the submandibular and parotid glands should be examined. The echogenicity of normal salivary glands is usually higher than that of the muscles and similar to that of the thyroid; however, it may be changed by fat infiltration associated with aging or obesity [42].

9. It is recommended to follow the OMERACT consensus four-grade semiquantitative scoring system. The typical abnormalities observed in patients

Table 4 Scintigraphy for the diagnosis of SS

\begin{tabular}{lllllll}
\hline Author & N & Sensitivity (\%) & Specificity (\%) & PPV (\%) & NPV (\%) & Accuracy (\%) \\
\hline Pennec 1993 [10] & 86 & 75 & 75 & 90 & - & - \\
Vitali 1993 [11] & 324 & 80 & 86 & - & - & - \\
Salaffi 2008 [18] & 156 & 70 & 82 & - & - & - \\
Vitali 1994 [22] & 151 & 87 & 79 & 50 & 93 & - \\
Tonami 2001 [28] & 130 & 86 & 89 & 94 & - \\
Tensing 2003 [32] & 43 & 47 & 86 & - & - & - \\
Milic 2009 [32] & 135 & 67 & 61 & - & - & -
\end{tabular}

PPV Positive predictive value, NPV Negative predictive value 
with SS are parenchymal inhomogeneity, reduced echogenicity and hypoechoic areas [43].

Several SGUS scoring systems have been suggested [42, 44-46] (Table 5). The first was published by De Vita et al. in 1992; the parameters included the gland size, echogenicity and homogeneity [34]. In a comparison of patients with SS with individuals with dry mouth and healthy controls, parenchymal echogenicity (mild, evident or gross inhomogeneity) was the best parameter to distinguish between patients with SS and healthy controls. A simplified assessment and standardized quantification were achieved using an US score for gland heterogeneity (ranging from 0 to 6 points), which attained a sensitivity of 88.8 and $53.8 \%$ for patients with pSS and patients with sSS respectively, and a specificity of 84.6 and $92.2 \%$ compared to controlsindividuals presenting dry mouth or healthy individuals, using a cut-off $>0$ [34].

Hocevar et al. analyzed the parotid and submandibular glands of patients with suspected SS based on the following parameters: echogenicity, inhomogeneity, number of hypoechogenic areas, hyperechogenic reflections and clearness of the borders of the salivary glands. The scores of the five parameters for all four salivary glands were summed, with the global score ranging from 0 to 48 points. All five parameters were associated with pSS. A cut-off score of $\geq 17$ points resulted in the best specificity (98.7\%) to sensitivity (58.8\%) ratio. Two examiners who were blinded to the diagnoses tested the reproducibility of this semiquantitative scoring system. The inter-rater agreement was high for the global score $(0.90)$, gland homogeneity (0.90), echogenicity (0.88) and hypoechogenic areas (0.88) [42].

Cornec et al. tested a modification of De Vita's score using a prospective cohort of patients with suspected SS who were subjected to SGUS. The echo structure of the parotid and submandibular glands (bilaterally) was scored from 0 to 4 points and the gland size was measured; the blood flow to the parotid gland was assessed by analyzing Doppler waveforms [44]. The Doppler waveform analysis and gland size measurements showed poor diagnostic performance, while echogenicity provided the best diagnostic value. The highest score among the four glands provided the best diagnostic value, and the optimal cut-off score was $\geq 2$ points (62.8\% sensitivity and $95.0 \%$ specificity). Although adding SGUS to the AECG criteria had no effect on specificity, it increased the sensitivity from 77.9 to $87 \%$.

A simplified scoring system was suggested in which parenchymal homogeneity in the major salivary glands was scored from 0 to 3 points to improve the inter and intra observer US reliability [45, 46]. Grade 0 is interpreted as normal, grade 1 (mild inhomogeneity) as normal or unspecific and grades 2 (several rounded hypoechoic areas) and 3 (numerous or confluent hypoechoic areas) as typical pSS. This simplified scale was tested by Theander and Mandl [45] and Hammenfors et al. [46]. Typical lesions were observed in $52 \%$ of the patients with pSS and in $1.8 \%$ of controls. The specificity and PPV of SGUS abnormalities typical of pSS were $98 \%$, the sensitivity was $52 \%$ and the NPV was 53\% [45]. Interestingly, pathological abnormalities were most frequent and most severe in the submandibular glands compared to the parotid glands.

International efforts currently seek to standardize the interpretation of SGUS for SS. In a recent study, an expert panel established that echogenicity and homogeneity are the parameters with the highest reproducibility and accuracy. While both pairs of parotid and submandibular glands should be examined, SGUS of the former was associated with better inter-rater reproducibility [48]. The OMERACT group published a consensus fourgrade semiquantitative scoring system (from 0 to 3 ) for the PGs and SMGs in patients with pSS was defined grade 0 , normal parenchyma; grade 1 , minimal change: mild inhomogeneity without anechoic/hypoechoic areas; grade 2 , moderate change: moderate inhomogeneity with focal anechoic/hypoechoic areas; grade 3, severe change: diffuse inhomogeneity with anechoic/hypoechoic areas occupying the entire gland surface. The final interpretation should consider the highest/severe score [43].

Studies aiming to establish whether SGUS provides evidence of normal glandular tissue or abnormalities typical of SS are relevant for clinical practice. When the glandular structure appears homogeneous and normal, SS might still be diagnosed based on clinical features and serological and immunological findings. In any case, normal or mildly abnormal findings are indicative of a good prognosis [48]. When SGUS is neither entirely normal nor clearly pathological, we recommend reassessing patients 6 to 12 months later. When SGUS identifies abnormalities typical of pSS, a diagnosis may be established with a reasonable degree of reliability, but should always be based on the clinical presentation and the results of laboratory tests. SGUS findings typical of pSS (grades 2 and 3) are also prognostic markers and the patient should be monitored closely by a rheumatologist $[41,49]$.

\section{Dry eye complaints should be assessed using validated questionnaires.}

Dry eye affects $85-98 \%$ of patients with pSS, mainly due to decreased basal tear secretion [50, 51]. Eye involvement usually leads to keratoconjunctivitis sicca (KCS), which is characterized by chronic irritation and abnormal changes in the corneal and conjunctival epithelium [52]. Signs and symptoms include eye redness, itch, a gritty feeling, burning or foreign body sensation and light sensitivity [52]. Approximately half (43\%) of 
Table 5 Scoring systems for salivary gland ultrasound findings in patients with Sjögren's syndrome, considering the bilateral submandibular glands and parotid glands

\begin{tabular}{|c|c|c|}
\hline Author (year) & Scoring & Calculation \\
\hline \multirow[t]{4}{*}{ De Vita (1992) [34] } & 0-normal & \multirow{4}{*}{$\begin{array}{l}\text { Range } 0-6 \text { points } \\
\text { Scores (0-3 points) are individually calculated for } \\
\text { each pair of parotids and submandibular glands. } \\
\text { When the degree of inhomogeneity differs } \\
\text { between a pair of glands, the highest degree is } \\
\text { considered. } \\
\text { Cut-off } \geq 2 \text { points for individual gland (or } 4 \text { points } \\
\text { total) }\end{array}$} \\
\hline & 1-Mild: small localized or diffuse hypoechoic areas & \\
\hline & $\begin{array}{l}\text { 2-Evident: multiple scattered hypoechoic areas of } \\
\text { variable size with an inhomogeneous distribution } \\
\text { and/or multiple or linear hyperechoic bands } \\
\text { without an acoustic shadow }\end{array}$ & \\
\hline & $\begin{array}{l}\text { 3-Gross: large rounded or confluent hypoechoic } \\
\text { areas and/or gross linear hyperechoic bands and/or } \\
\text { multiple cysts or multiple calcifications, resulting in } \\
\text { severe damage to the gland architecture }\end{array}$ & \\
\hline \multirow[t]{27}{*}{ Hocevar (2005) [42] } & Parenchymal echogenicity & \multirow{27}{*}{$\begin{array}{l}\text { Range } 0-48 \text { points } \\
\text { The scores for the } 5 \text { parameters in the } 4 \text { glands } \\
\text { are added. } \\
\text { Cut-off } \geq 17 \text { points }\end{array}$} \\
\hline & 0-comparable to the thyroid & \\
\hline & 1-decreased compared to the thyroid & \\
\hline & Homogeneity & \\
\hline & 0-homogeneous gland & \\
\hline & 1-mild inhomogeneity & \\
\hline & 2- evident inhomogeneity & \\
\hline & 3-grossly inhomogeneous gland & \\
\hline & Presence of hypoechogenic areas & \\
\hline & 0-absent & \\
\hline & 1-a few, scattered & \\
\hline & 2-several & \\
\hline & 3-numerous & \\
\hline & Hyperechogenic reflections & \\
\hline & Parotids & \\
\hline & 0-absent & \\
\hline & 1-a few, scattered & \\
\hline & 2-several & \\
\hline & 3-numerous & \\
\hline & Submandibular glands & \\
\hline & 0-absent & \\
\hline & 1-present & \\
\hline & Clearness of salivary gland borders & \\
\hline & 0-clear, regular defined borders & \\
\hline & 1-partially defined borders & \\
\hline & 2-ill-defined borders & \\
\hline & 3-borders not visible & \\
\hline \multirow{5}{*}{$\begin{array}{l}\text { Cornec (modified } \\
\text { De Vita) (2013) [44] }\end{array}$} & 0-normal & \multirow{5}{*}{$\begin{array}{l}\text { Range } 0-16 \text { points } \\
\text { Maximum score of } 4 \text { points for each individual } \\
\text { gland } \\
\text { The final score is calculated by adding the highest } \\
\text { score for each gland. } \\
\text { Cut-off } \geq 2 \text { points for individual gland (or } 8 \text { points } \\
\text { total) }\end{array}$} \\
\hline & $\begin{array}{l}\text { 1-small hypoechogenic areas without echogenic } \\
\text { bands }\end{array}$ & \\
\hline & $\begin{array}{l}\text { 2-multiple hypoechogenic areas measuring }<2 \\
\text { mm with echogenic bands }\end{array}$ & \\
\hline & $\begin{array}{l}\text { 3-multiple hypoechogenic areas measuring 2-6 } \\
\text { mm with hyperechogenic bands }\end{array}$ & \\
\hline & $\begin{array}{l}\text { 4-multiple hypoechogenic areas measuring }>6 \\
\text { mm or multiple calcifications with echogenic bands }\end{array}$ & \\
\hline Theander (2014) [45] & 0-the parenchyma is completely homogeneous & Range $0-3$ points \\
\hline
\end{tabular}


Table 5 Scoring systems for salivary gland ultrasound findings in patients with Sjögren's syndrome, considering the bilateral submandibular glands and parotid glands (Continued)

\begin{tabular}{|c|c|c|}
\hline Author (year) & Scoring & Calculation \\
\hline & 1-mildly inhomogeneous & The highest score among the 4 glands is \\
\hline & 2-several rounded hypoechoic lesions & $\begin{array}{l}\text { Considered. } \\
\text { Score of } 0-1 \text { points: normal or unspecific }\end{array}$ \\
\hline & $\begin{array}{l}\text { 3-rounded hypoechoic lesions are numerous } \\
\text { or confluent }\end{array}$ & $\begin{array}{l}\text { Score of 2-3 points: abnormal, typical of } \\
\text { Sjögren's syndrome }\end{array}$ \\
\hline \multirow[t]{4}{*}{ aHammenfors (2015) [46] } & 0-normal & \multirow{4}{*}{$\begin{array}{l}\text { Range 0-3 points } \\
\text { The highest score among the } 4 \text { glands is considered. } \\
\text { Score of 0-1 points: normal or nonspecific } \\
\text { Score of 2-3 points: abnormal and typical } \\
\text { of Sjögren's syndrome }\end{array}$} \\
\hline & 1-a few minor focal hypo/anechoic areas & \\
\hline & $\begin{array}{l}\text { 2-at least one of the glands is more severely } \\
\text { affected, with multiple focal hypo-/anechoic } \\
\text { areas, but some homogeneous and } \\
\text { normal-appearing salivary gland tissue remains }\end{array}$ & \\
\hline & $\begin{array}{l}\text { 3-severe generalized effects on at least } 2 \text { of the } \\
\text { glands, with minimal normal-appearing glandular } \\
\text { tissue remaining, as well as at least a grade } 2 \\
\text { effects on the remaining gland(s). }\end{array}$ & \\
\hline \multirow[t]{4}{*}{ Jousse-Joulin (2019) [43] } & 0-normal & \multirow{4}{*}{$\begin{array}{l}\text { Score of 2-3 points: abnormal and typical } \\
\text { of Sjögren's syndrome }\end{array}$} \\
\hline & 1-mild or unspecific and few hypoechoic areas. & \\
\hline & $\begin{array}{l}\text { 2-multiple focal hypo-/anechoic areas, but some } \\
\text { homogeneous and normal-appearing salivary } \\
\text { gland tissue remains. }\end{array}$ & \\
\hline & $\begin{array}{l}\text { Diffuse and multiple focal hypo-/anechoic. No } \\
\text { normal appearence areas salivary gland tissue. }\end{array}$ & \\
\hline
\end{tabular}

${ }^{\text {aAdapted from reference [47] }}$

patients with SS report experiencing these complaints for more than 5 years, one-fourth exhibit eye redness at least half of the time, and $25 \%$ are unable to produce tears [50, 53]. Reported dry and gritty eye exhibited reasonable sensitivity ( 84.9 and $73.5 \%$, respectively) and specificity ( 80 and $73.8 \%$, respectively) to distinguish between patients with SS and controls [22]. Unfortunately, a weak correlation was observed between subjective complaints and objective ophthalmological findings. Chronic inflammation impairs the corneal sensitivity and decreases the occurrence of SS symptoms. This discrepancy between subjective complaints and findings from an ophthalmological examination may delay the diagnosis of SS for up to 10 years [54-56]. The Tear Film and Ocular Surface Society (TFOS) Dry Eye Workshop (DEWS II) Diagnostic Methodology Subcommittee identified the tests used to diagnose and monitor dry eye disease (DED) and indicated those that are the most appropriate for diagnosis and sub classification (as predominantly evaporative or aqueousdeficient). DEWS II also established the most appropriate order and technique to perform these tests, ideally in a noninvasive manner [57-60]. The Ocular Surface Disease Index (OSDI) assesses eye symptoms in patients with dry eye by focusing on three aspects: eye symptoms in the past 7 days, possible environmental triggers of eye discomfort and limitations in the activities of daily living caused by dry eyes. OSDI scores are interpreted as follows: 0-12 points, normal; $13-22$ points, mild dry eye; $23-32$ points, moderate dry eye; and 33-100 points, severe dry eye [61].
The OSDI exhibited a sensitivity of $89 \%$ and specificity of $72 \%$ in the comparison of patients with pSS and patients with KCS $[57,62]$.

11. Preliminary tear film testing should include the Schirmer I test and ocular surface/cornea (fluorescein) and conjunctiva (lissamine green) staining at a minimum. The order of the tests affects the results.

An ophthalmological examination is very important for the diagnosis of SS, as is the order of and the intervals between tests, because they can affect the results. The tests should be performed in order from the least to the most invasive tests [63]. The total duration of an ophthalmological examination is approximately $20 \mathrm{~min}$ [50].

The Schirmer I test (without anesthetic) should be the first eye test performed, followed by fluorescein and lissamine green staining. This order is the most appropriate because changes might occur in the tear film following the administration of substances to the ocular surface, leading to erroneous results.

12. The Schirmer I test should be the first eye test performed because its results change after the tear breakup time and staining tests. A Schirmer I test $\leq$ $5 \mathrm{~mm}$ is a diagnostic criterion for SS.

The Schirmer I test measures the tear volume and thus is able to confirm a severe aqueous deficiency, which 
occurs in patients with SS. It represents an estimate of reflex tear production [64]. This test was not recommended by DEWS II for the diagnosis of dry eye but was maintained as a recommendation for the diagnosis of SS [4]. A $5-\mathrm{mm} \times 35-\mathrm{mm}$ strip of filter paper is used to measure tear production over time. The paper strip is carefully placed between the middle and temporal thirds of the bilateral lower lids and the patient is instructed to keep the eyes open or closed for $5 \mathrm{~min}$. Afterwards, the moistened paper is measured with a millimeter ruler. A Schirmer I test result of $\leq 5 \mathrm{~mm}$ of wetting is considered abnormal and a diagnostic criterion for SS [2,51]. It exhibits sensitivity of $42 \%$ and specificity of $76 \%$ in a comparison of patients with pSS and individuals with dry symptoms, and sensitivity of $76.9 \%$ and specificity of $72.4 \%$ in a comparison of patients with pSS and controls [22, 62].

\section{If performed, the tear breakup time (TBUT) test should be the second assessment of dry eye. A $T B U T<10 \mathrm{~s}$ (mean of 3 measurements) is considered abnormal.}

The second step in the ophthalmological examination consists of the administration of $0.5 \%$ or $1 \%$ fluorescein eye drops. The patient is instructed to blink three times to distribute the dye across the ocular surface and then to stop blinking until he/she is asked to blink again. The tear breakup time (TBUT) is measured with a slit lamp at 10x magnification with maximum illumination and a blue cobalt filter. The TBUT is defined as the time in seconds between the last blink and the appearance of dry spots on the corneal surface $[51,65]$. The test should be repeated three times, and a mean TBUT $<10 \mathrm{~s}$ is considered abnormal. When patients with pSS classified according to the American-European Consensus (2002) group were compared with control group with dry eye symptoms without autoimmune disease, Versura et al. demonstrated that the BUT performed poorly as a diagnostic test for pSS (sensitivity of 92\%, specificity of $17 \%$ and Likelihood ratio: 1.11) [62].

\section{Ocular surface staining (fluorescein and lissamine} green) should be assessed using the van Bijsterveld scale $(\geq 4)$ or the SICCA Ocular Staining Score (OSS) $(\geq 5)$. Rose Bengal staining should no longer be performed due to its toxicity to the epithelium at the ocular surface.

Ocular surface staining is performed to assess damage to the ocular surface. In the present case, it involves administering dyes in an ophthalmic solution to diagnose dry eye. The dyes most commonly used for this purpose are sodium fluorescein, Rose Bengal and lissamine green. Fluorescein stains cells that have lost their integrity [66].
Previous staining techniques also included Rose Bengal to score both the cornea and the conjunctiva. This dye stains goblet cells, keratinized epithelial cells and corneal and conjunctival cells undergoing apoptosis. However, Rose Bengal is toxic to the epithelial cells in the cornea and conjunctival surface, and thus it has been banned [51, 65]. According to one report, the sensitivity and specificity of Rose Bengal for patients with primary and secondary SS were 64.3 and $81.7 \%$, respectively [22]. In one study, among non-invasive techniques, Rose Bengal ocular staining was the best non invasive procedure to discriminate pSS patients from patients with KCS [66].

Lissamine green is less toxic to the ocular surface and is better tolerated. It only stains cells with membrane lesions. Thus, it replaced Rose Bengal for assessments of dry eye. Several scores are available to measure the severity of lesions, including the OSS and van Bijsterveld's scale. SICCA developed the OSS to characterize KCS associated with SS, which includes fluorescein staining to score corneal lesions and lissamine green staining to score the bulbar conjunctiva [51]. OSS is a validated test and exhibits a high inter-rater concordance among trained ophthalmologists [67]. In the fluorescein staining test, each cornea is examined using a slit lamp with a cobalt blue filter 6 to $8 \mathrm{~min}$ after instillation. Stained punctate epithelial erosions (PEEs) are counted and scored as follows: 0 points, no PEEs; 1 point, 1 to 5 PEEs; 2 points, 6 to 30 PEEs; and 3 points, $>30$ PEEs. The maximum score is 6 points, because an additional point is recorded when PEEs are located in the central 4-mm diameter portion of the cornea, some mucous filaments are observed on the cornea or one or more patches of confluent staining are observed on the cornea [52].

The external eye should be examined with a slit lamp after the fluorescein instillation and before the application of lissamine green. The examiner should search for abnormalities of the lids, conjunctiva and cornea. Some conditions might interfere with the results of the OSS, such as lagophthalmos, entropion, pterygium, pinguecula, blepharitis and meibomitis [51].

Next, one drop of lissamine green is applied to the inferior conjunctival fornix of both eyes. The examination should be performed immediately using a slit lamp with white light or a neutral density filter. The patient is instructed to blink several times to keep the dye from pooling in the conjunctival folds, which can confound the results. On the OSS, grade 0 corresponds to 0 to 9 dots of lissamine green staining, grade 1 to 10 to 32 dots, grade 2 to 33 to 100 dots, and grade 3 to more than 100 dots or any area of confluent staining $\geq 4 \mathrm{~mm}^{2}$. The interpalpebral bulbar conjunctiva is the proper site for assessment; the nasal and temporal bulbar conjunctiva are graded separately, with a maximum score of 3 points each. Thus, the maximum score is 6 points for each eye 
[51, 63, 65]. Versura et al. demonstrated that the vital dye (Lissamine green) staining showed statistically significant differences (sensitivity 0.63 ; specificity 0.89 ; Likelihood ratio: 5.72) between patients with primary SS classified according to the American-European Consensus Group (2002) and individuals with xeroftalmia without serological positivity for any autoimmune disease [62].

The total OSS score is obtained by adding the scores for the fluorescein and lissamine green staining tests. Each eye is scored separately, for a maximum score of 12 points. Scoring should not include stained pinguecula, pterygia and artifacts caused by Schirmer strips [53]. The van Bijsterveld scale is assessed using the same dyes. The ocular surface is divided into three areas: nasal bulbar conjunctiva, temporal bulbar conjunctiva and cornea. Each area is attributed a score ranging from 0 to 3 points $(0$ points: no staining; 3 points: confluent staining). The maximum score for each eye is 9 points $[63,68]$.

15. The levels of anti-HEp-2 antinuclear antibodies (ANAs), anti-Ro/SSA antibodies, anti-La/SSB antibodies and rheumatoid factor should be measured for all patients with suspected SS. These tests are useful for determining the diagnosis and prognosis.

Many non-organ-specific and organ-specific autoantibodies have been detected in the serum of patients with pSS.

ANAs are detected in greater than $70 \%$ of patients with pSS, and the fine speckled pattern is the most frequent pattern detected using indirect immunofluorescence, combined with presence of anti-Ro/SSA and anti-LA/SSB antibodies [69]. Other, less frequent ANA patterns include the centromere and the anti-NuMA patterns (nucleus and mitotic apparatus staining) [69].

Although not specific for pSS, the anti-Ro/SSA and anti-LA/SSB antibodies are frequently detected in approximately $50-90 \%$ and $25-60 \%$ of patients, respectively (as a function of the detection technique used and the characteristics of the analyzed population) [69] and represent one of the main classification criteria [2-4]. These autoantibodies are also associated with a higher frequency of systemic manifestations and a greater extent of lymphocytic infiltration in the salivary glands [69-71].

The 52-kDa Ro and $60-\mathrm{kDa}$ Ro and La proteins combine to produce 4 RNA particles (small RNAs), forming a highly conserved antigenic complex in the nucleus and cytoplasm of different cells. This complex appears to be involved in the mechanisms of cell proliferation. These proteins exhibit different linear or conformational antigenic epitopes that are recognized by antibodies present in the serum of patients with various diffuse connective tissue diseases [69-72]. In addition to pSS, the Ro/La complex of proteins represent a relevant antigenic target in several autoimmune diseases, such as SLE, subacute cutaneous lupus erythematosus, neonatal lupus, inflammatory myopathies, SSc, RA and primary biliary cholangitis (PBC) [72]. Although anti-La/SSB autoantibodies are not specific markers, they are more frequently associated with pSS compared to other systemic autoimmune diseases [69-72]. This finding is relevant in clinical practice, since these antibodies in combination with the clinical characteristics and laboratory test results might contribute to distinguishing between pSS and other autoimmune diseases, such as SLE, SSc and RA [73].

The relevance of the anti-Ro/SSA and anti-La/SSB antibodies for the diagnosis of pSS is widely acknowledged, and they represent one of the main aspects of the 2002 [2] and 2012 [3] pSS classification criteria. The relevance of the anti-Ro/SSA antibody was recently ratified in the 2016 ACR/EULAR pSS classification criteria [4]. The most significant aspects, with the highest weight for classification in the latter system, are anti-Ro/SSA antibody positivity and a histological examination of the minor salivary glands, with a focus score $\geq 1$ [4]. In contrast, the anti-La/SSB antibody was excluded from the most recent classification criteria, because a recent study showed that this antibody alone (i.e., without anti-Ro/ SSA) is not associated with the pSS phenotype [74].

These antibodies also have clinical and prognostic implications. In a recent large-scale study with more than 10,000 patients with pSS, ANA, anti-Ro/SSA and antiLa/SSB antibody positivity at diagnosis correlated with positive results from a minor salivary gland biopsy [75]. Anti-Ro/SSA and anti-La/SSB antibodies are also associated with persistent parotid enlargement, a greater extent of inflammatory infiltration in the salivary glands, lymph node involvement, spleen enlargement, vasculitis, Raynaud's phenomenon, arthritis, renal tubular acidosis, peripheral neuropathy and effects on the lung [70]. AntiRo/SSA 60-kd is associated with more serious and extensive CNS disease [76]. Interestingly, anti-Ro/SSA and anti-La/SSB antibodies have been detected up to 20 years before a diagnosis of pSS is established, as evidenced by the observation that more than half of the asymptomatic mothers of infants with neonatal lupus subsequently developed autoimmune diseases, mainly pSS and SLE [77]. Similar findings were reported for a series of patients with pSS for whom serum samples collected years before diagnosis were available [78].

The detection of anti-Ro/SSA and anti-La/SSB antibodies during screening is achieved using indirect immunofluorescence (IIF) staining of HEp-2 cells as the substrate (ANA). These antibodies usually exhibit the fine speckled pattern (Fig. 1). However, clinicians should remember that $10 \%$ of anti-Ro/SSA-positive serum samples produce negative results on HEp-2 ANA tests [79]. ELISAs with purified or recombinant antigens are considered rapid, sensitive and 


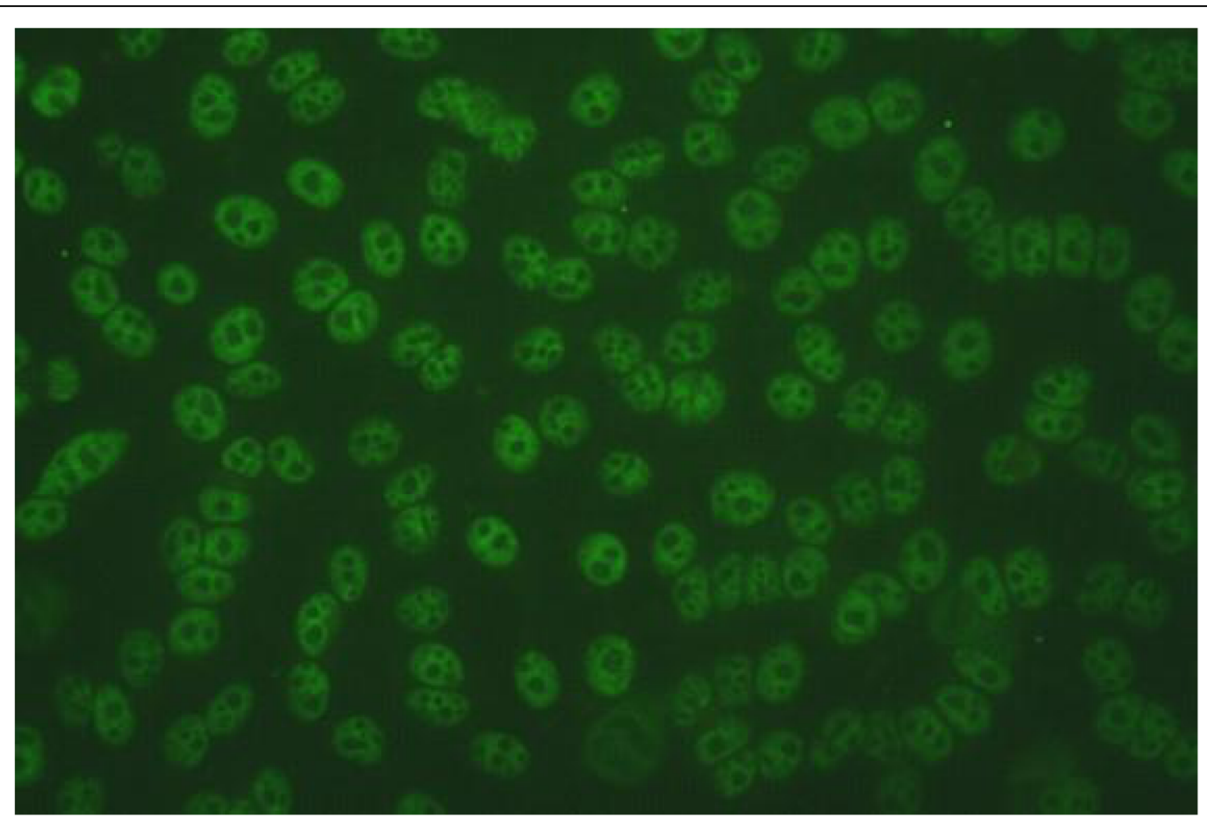

Fig. 1 Indirect immunofluorescence staining of HEp-2 cells exhibiting the nuclear fine speckled pattern of anti-Ro/SSA and anti-La/SSB antibodies (400x). Legend: Source: Central Laboratory Division and Medical Investigation Laboratory \#17, Clinical Hospital, School of Medicine, University of Sao Paulo (collaboration with Cleonice Bueno)

specific for the detection of anti-Ro/SSA and anti-La/SSB antibodies. Additional advantages are the automation and quantitative analysis. The most recently developed ELISA kits exhibit high sensitivity and specificity. A crucial aspect is the use of highly purified antigens to avoid false-positive results $[69,72,79]$. Immunoblotting (IB) is an additional available technique but is highly complex and difficult to perform. Despite its high specificity, IB is not recommended for routine investigations of these antibodies due to its high cost and mainly its low sensitivity to detect antiRo/SSA antibodies [69, 72, 79].

Finally, a strong association has been observed between the anti-Ro/SSA and anti-La/SSB antibodies; although the former has been detected alone in the serum samples from many patients, the latter usually appears in combination with anti-Ro antibodies $[69,79]$. Differences in the conformations of the Ro52 and Ro60 protein epitopes have been detected. Regarding the former, most sera recognize linear epitopes in the denatured molecule, which are not expressed on the surface of the native protein. In contrast, the epitopes recognized by the anti-Ro60 antibodies strongly depend on the conformation, and the antibodies largely lose their ability to bind to the denatured protein. As a result, anti-Ro52 antibodies are not detected using precipitation-based immunoassays or ELISAs when the native Ro/SSA protein is used as the antigen source. In addition, the antibodies do not exhibit any specific IIF staining pattern in the HEp-2 ANA test; the anti-Ro52 antibody alone might exhibit a cytoplasmic pattern [80, 81]. In summary, the anti-Ro52 antibodies are not usually detected with the classic methods used to investigate anti-Ro/SSA antibodies, which are more selective for the anti-Ro60 antibody. Additionally, the anti-Ro52 and anti-Ro60 antibodies might mask one another, and greater than $20 \%$ of Ro/SSApositive serum samples might not be detected in assays using both antigens in combination. Therefore, the antiRo52 and anti-Ro60 antibodies should be analyzed separately [80, 82]. Rheumatoid factor (RF) is detected in 36 to $74 \%$ of patients with pSS and is associated with a greater severity of salivary gland lesions $[69,70]$. Table 6 describes the main laboratory tests used for the diagnosis, differential diagnosis compared with other systemic autoimmune diseases, assessment of disease activity, diagnosis of systemic manifestations and assessment of drug toxicity.

\section{Minor (labial) salivary gland biopsy (MSGB) is the} diagnostic criterion with the highest sensitivity and specificity and should be performed to confirm the diagnosis in all patients with suspected SS who test negative for anti-Ro/SSA antibodies. The linear incision technique with the collection of at least 4-6 glands or $8 \mathrm{~mm}^{2}$ of gland tissue is recommended.

Focal lymphocytic infiltration occurs in all organs affected by SS and is associated with diverse clinical manifestations of the disease. To date, the salivary glands have been the most thoroughly studied among the organs affected by SS.

Minor (labial) salivary gland biopsy (MSGB) is the most widely used and technically simple procedure. The linear 
Table 6 Main diagnostic tests for the assessment of patients with primary Sjögren's syndrome

\begin{tabular}{|c|c|c|c|c|c|c|}
\hline & Diagnosis & $\begin{array}{l}\text { Organ } \\
\text { involvement }\end{array}$ & $\begin{array}{l}\text { Disease } \\
\text { activity }^{a}\end{array}$ & $\begin{array}{l}\text { Drug } \\
\text { toxicity }\end{array}$ & $\begin{array}{l}\text { Associated } \\
\text { autoimmune } \\
\text { diseases }\end{array}$ & Comorbidities \\
\hline Complete blood count & & $x$ & $x$ & X & $x$ & \\
\hline $\begin{array}{l}\text { Urea, creatinine, sodium, and potassium levels } \\
\text { Venous blood gas level } \\
\text { Urinalysis } \\
\text { 24-h urine protein or urine protein/creatinine levels }\end{array}$ & & $x$ & $x$ & $x$ & & $x$ \\
\hline $\begin{array}{l}\text { Blood sugar levels } \\
\text { Levels of total cholesterol and its fractions and triglycerides }\end{array}$ & & & & $x$ & & $x$ \\
\hline Levels of transaminases and canalicular enzymes & & & & $x$ & $x$ & \\
\hline Creatine phosphokinase levels & & $x$ & $x$ & & & \\
\hline Protein electrophoresis & & $x$ & $x$ & & $x$ & \\
\hline Chest radiograph High-resolution computed tomography of the lungs & & $x$ & $x$ & & & \\
\hline Electroneuromyography & & $x$ & $x$ & & & \\
\hline Magnetic resonance imaging of the head & & $x$ & $x$ & & & \\
\hline Anti-Ro/SSA and anti-La/SSB antibodies & $x$ & & & & & \\
\hline C3/C4 levels & & $x$ & $x$ & & & \\
\hline $\begin{array}{l}\text { Levels of free T4, TSH, anti-thyroid peroxidase, anti- thyroglobulin, } \\
\text { nti-mitochondrial, anti-smooth muscle, anti-gastric parietal cell antibodies }\end{array}$ & & & & & $x$ & \\
\hline Saliva flow rate & $x$ & & & & & \\
\hline Salivary gland scintigraphy & $x$ & & & & & \\
\hline Salivary gland ultrasound & $x$ & & & & & \\
\hline Minor salivary gland biopsy & $x$ & & & & & \\
\hline
\end{tabular}

${ }^{a}$ Disease activity according to the EULAR Sjögren's Syndrome Disease Activity Index (ESSDAI). Anti-dsDNA, anti-RNP, anti-Sm and anti-Scl-70 antibodies are useful for a differential diagnosis compared with other systemic autoimmune rheumatic diseases

incision technique is the most frequently performed procedure and is associated with a low rate of complications of $<1 \%$ [83-85].

International recommendations were published to standardize the histopathological examination of MSGB samples in clinical trials; however, they are also useful to guide and standardize clinical practice. Based on these recommendations and the experience of the salivary gland experts who participated in the present study, we recommend the collection of at least 4-6 glands or $8 \mathrm{~mm}^{2}$ of gland tissue. The samples should be stored in buffered 10\% formaldehyde for hematoxylin-eosin (HE) staining. Special stains for the quantification of fibrosis, immunohistochemical analysis and immunofluorescence staining are not necessary in a routine morphological diagnostic investigation. Immunohistochemical staining is needed in patients with suspected lymphoma associated with IgG4-related disease [85].

According to the 2016 ACR/EULAR criteria, a salivary gland biopsy should be mandatorily performed for patients testing negative for the anti-Ro/SSA antibody [4]. The sensitivity (63.5-93.7\%) and specificity (61.2-100\%) of this method are high, $>80 \%$ in most studies [85], with a PPV of $95 \%$ and NPV of $92.6 \%$ [86].
17. The histological pattern compatible with SS is focal lymphocytic sialadenitis (FLS) with focus score $\geq 1$, which corresponds to at least one focus (a cluster of 50 or more lymphocytes) in periductal or perivascular areas adjacent to normal acini in a 4$\mathrm{mm}^{2}$ gland section.

Focal lymphocytic sialadenitis (FLS) with focus score $\geq$ 1 is the main histological pattern associated with SS. FLS was described 50 years ago [87-89], was included as a diagnostic criterion for the first time in 1975 and has been included in all classification criteria since then [89]. FLS is characterized by one or more foci consisting of dense clusters of 50 or more lymphocytes (most comprise several hundred or more) that are usually located in periductal or perivascular areas adjacent to normal mucous acini in lobes without duct dilation or fibrosis and are associated with a discrete plasmacytic infiltrate. A focus score of 1 corresponds to one lymphocytic focus in a 4- $\mathrm{mm}^{2}$ gland section $[2,3,90,91]$. The degree of inflammatory activity is classified based on the intensity of the inflammatory infiltrate as mild and unspecific (grades 1 and 2), a focus score $=1$ (grade 3 ) and a focus score $>1$ (grade 4) [87]. When the predominant pattern 
is characterized by unspecific abnormalities, such as acinar atrophy, duct dilation, fibrosis and fatty infiltration, it cannot be classified as FLS [85]. Foci adjacent to areas with atrophy are expected to be detected in glands with severe, advanced, chronic SS lesions.

\section{Nonspecific histological patterns}

In addition to FLS with a focus score $\geq 1$, other nonspecific patterns were described in a cohort of 1726 patients with suspected SS: FLS with a focus score $<1$ and chronic non specific sialadenitis (CNSS) and chronic sclerosing/atrophic sialadenitis (CSS). Compared to FLS with a focus score $<1$ and CNSS/CSS, FLS with a focus score $\geq 1$ exhibited a strong correlation with the main phenotypic characteristics of SS [92].

\section{Focus score calculation}

The presence of FLS predominant pattern should be established before calculating the focus score. To calculate focus score, foci surrounded by healthy glandular tissue should be taken in account. The focal score is obtained by the formula [85-92]: FOCAL SCORE = (TOTAL NUMBER OF FOCI $\div$ WHOLE GLANDULAR SURFACE) X 4.

The glandular surface area can be measured with a millimeter ruler, reticle, or high-resolution morphometry on scanned images. For a focus score $>10$, foci are typically confluent, and a ceiling score of 12 may be applied [85].

As mentioned above, only foci surrounded by a normal parenchyma should be considered to establish the FLS pattern. For research, it has been proposed, in patients with well-defined diagnosis (when the predominant pattern is compatible with SS), all the foci could be considered in the calculation of the total focus score, including foci located close to areas with atrophy [85]. The mononuclear infiltrate area has also been used as biomarker in clinical trials; however, it requires high-resolution morphometry and has not yet been included in clinical practice [85].

The lymphocytic foci predominantly display a characteristic periductal location but can also occur around vessels and in the parenchyma. T CD4+ cells predominate in the smaller clusters, and $\mathrm{B}$ cells predominate in the larger clusters. The frequency of $\mathrm{CD} 8+$ and natural killer (NK) cells does not vary as a function of the lesion severity. In turn, the frequency of regulatory $\mathrm{T}$ cells (Treg) vary as a function of lesion severity and are more frequently observed in medium-sized clusters [85].

\section{Germinal centers and lymphoepithelial lesions}

Germinal center (GC)-like structures are lymphoid infiltrates that resemble the germinal centers of secondary lymphoid organs and are detected in $17-25 \%$ of MSGB samples from patients with SS. They consist of segregated $\mathrm{T}$ and $\mathrm{B}$ cell zones and follicular dendritic cells within areas of activated and proliferating $\mathrm{B}$ cells. The

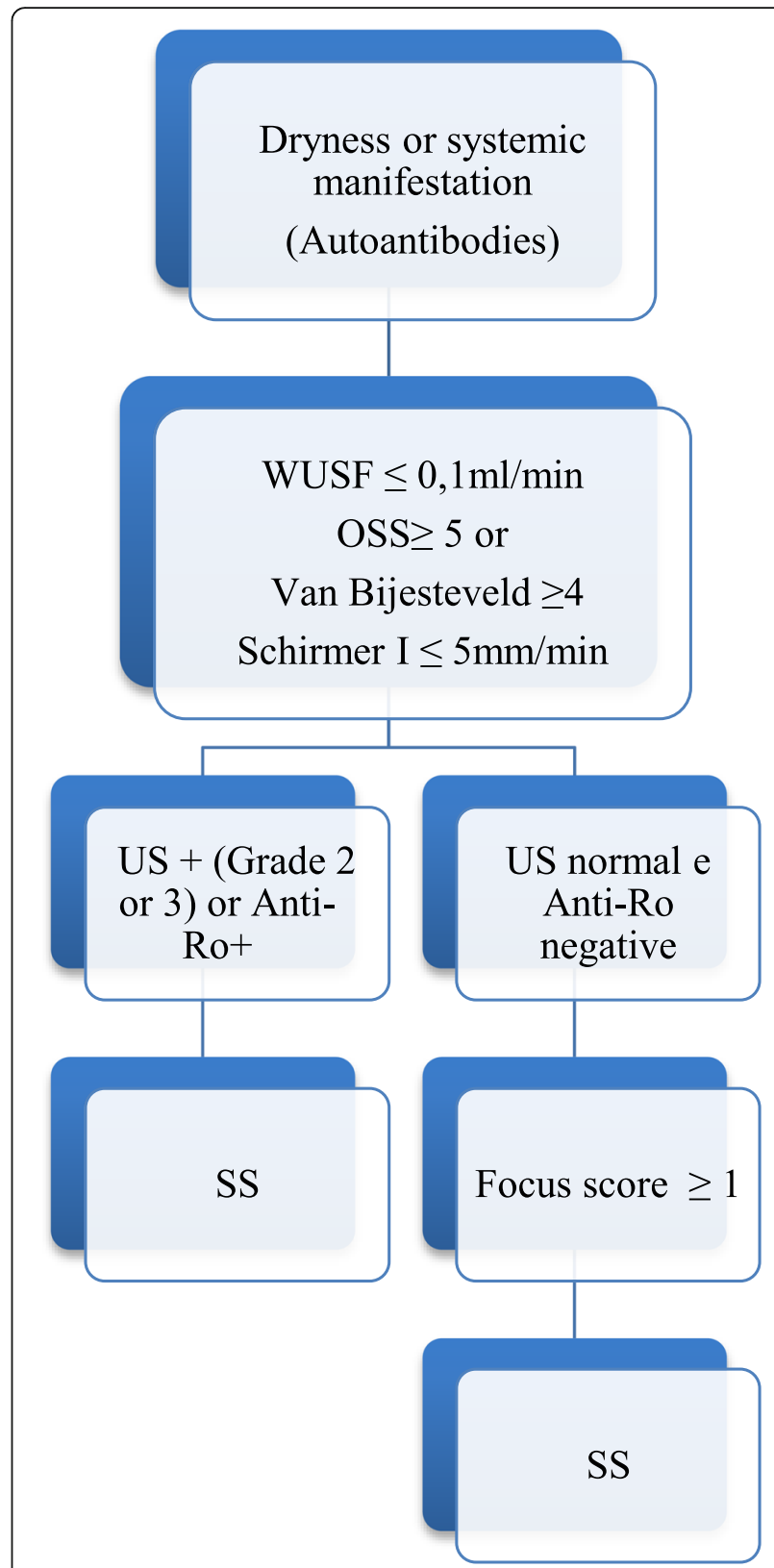

Fig. 2 Diagnosis of Primary Sjogren's Syndrome

formation of GC-like structures is accompanied by the ectopic production of the lymphoid chemokines CXC chemokine ligand 13 (CXCL13), C-C motif chemokine ligand 21 (CCL21) and CXCL12 [85, 93-97].

The presence of GC-like structures should be described in biopsy reports. While HE staining suffices to detect GC-like structures in clinical practice, additional staining for B cell lymphoma 6 (BCL-6), CD21 (a marker of follicular dendritic cells) and CD3 and CD20 (to calculate the $\mathrm{T} / \mathrm{B}$ cell ratio) can be performed for research purposes [85]. 
Lymphoepithelial sialadenitis (LESA) or myoepithelial sialadenitis (MESA) are characterized by lymphocytic infiltration of ducts and basal cell hyperplasia, resulting in a multilayered epithelium. LESA is more commonly observed in the parotid tissue and should also be included in biopsy reports [85].

\section{MSGB is recommended for all patients to assess the prognosis, degree of inflammation and chronicity, and should be performed at the discretion of the attending physician in a shared decision with the patient.}

In addition to its contribution to the diagnosis of SS, an MSGB at the start of the follow-up period provides a measure of the tissue aggressiveness of the disease, has prognostic value and ideally should be performed in all patients [93].

A focus score $\geq 3$ and presence of GC-like structures and LESA (MESA) are associated with a higher frequency of extraglandular manifestations, higher disease severity, gland dysfunction [92, 93] and higher risk for lymphoma [93-98].

The presence of GC-like structures was associated with a higher risk of marginal zone lymphoma in studies conducted in Italy and Sweden, but this finding was not confirmed in another small study conducted in The Netherlands $[99,100]$. More recently, French researchers reported that the presence of GC-like structures was associated with 7.8 times higher risk of lymphoma [98].

Intervention studies reported an improvement of the inflammatory infiltrate after treatment. However, since a biopsy is an invasive method, there is no consensus regarding its indication for follow-up [99, 100].

\section{Conclusions}

The diagnosis of glandular manifestations of pSS is complex and multidisciplinary. It requires specific knowledge in the field of ophthalmology, immunology, pathology and imaging, making it compulsory for the rheumatologist to work with professionals from these different areas in order to improve accuracy and early diagnosis. Glandular dysfunction tests, ANA, RF, Anti-Ro, electrophoresis of protein, urinalysis, hemogram, C-Reactive protein, complement, serology for some virus (VDRL, HCV, HIV) and SGUS should be investigated when dryness or systemic manifestation are present. Minor salivary gland biopsy is recommended for all anti-Ro negative or incomplete criteria cases (Fig. 2).

\section{Supplementary information}

Supplementary information accompanies this paper at https://doi.org/10. 1186/s42358-019-0102-8.

Additional file 1. Quality Assessment and Risk of bias of the included studies.
Acknowledgements

Not applicable.

Authors' contributions

All of the authors provided critical review, relevant edits, and feedback to direct content during multiple rounds of review. In addition, all authors have read and approved the final version of this manuscript.

Funding

Not applicable.

Availability of data and materials

Not applicable.

Ethics approval and consent to participate

Not applicable.

Consent for publication

Not applicable.

Competing interests

The authors declare that they have no competing interests.

\section{Author details}

'Disciplina de Medicina de Urgência e Medicina Baseada em Evidências, Escola Paulista de Medicina-Universidade Federal de São Paulo (EPM-UNIFESP), Rua Botucatu 740 Vila Clementino, São Paulo, SP CEP: 04023-062, Brazil. ${ }^{2}$ Disciplina de Reumatologia, Universidade de Santo Amaro, Rua Enéas Siqueira Neto, Jardim das Embuias, São Paulo, SP CEP: 04829-300, Brazil. ${ }^{3}$ Disciplina de Reumatologia, Laboratório de Autoimunidade (DLC + LIM17), Hospital das Clínicas da Faculdade de Medicina da USP (HCFMUSP), R. Dr. Ovídio Pires de Campos, 225 - Cerqueira César, São Paulo, SP CEP: 05403-010, Brazil. ${ }^{4}$ Disciplina de Reumatologia, Hospital Federal dos Servidores do Estado do Rio de Janeiro, R. Sacadura Cabral, 178, Saúde, Rio de Janeiro, RJ CEP: 20221-903, Brazil. ${ }^{5}$ Disciplina de Reumatologia Departamento de Clínica Médica, Universidade Federal de Ciências da Saúde de Porto Alegre (UFCSPA), R. Sarmento Leite, 245 - Centro Histórico de Porto Alegre, Porto Alegre, RS CEP: 90050-170, Brazil. 'Serviço de Reumatologia, Universidade Federal de Santa Catarina, R. Profa. Maria Flora Pausewang, s/n - Trindade, Florianópolis, SC CEP: 88036-800, Brazil. Disciplina de Reumatologia, Departamento de Clínica Médica, Universidade Federal de Pernambuco, Av. Prof. Moraes Rego, 1235, Cidade Universitária, Recife, PE CEP: 50670-901, Brazil. ${ }^{8}$ Departamento de Oftalmologia, Escola Paulista de Medicina-Universidade Federal de São Paulo (EPM-UNIFESP), Rua Botucatu, 820, Vila Clementino, São Paulo, SP CEP: 04023-062, Brazil. ${ }^{9}$ Disciplina de Reumatologia, Departamento de Clínica Médica, FCM UNICAMP, R. Tessália Vieira de Camargo, 126 - Cidade Universitária, Campinas, SP CEP: 13083-887, Brazil. ${ }^{10}$ Disciplina de Reumatologia, Universidade Federal do Amazonas, Rua Afonso Pena, 1053, Manaus, AM CEP: 69020-160, Brazil. ${ }^{11}$ Disciplina de Reumatologia, Departamento de Medicina Interna, Centro de Ciências Médicas, Universidade Federal de Paraíba (UFPB), Campus I - Lot. Cidade Universitaria, Paraíba, PB CEP: 58051-900, Brazil. ${ }^{12}$ Universidade Federal do Espírito Santo, Departamento de Patologia, Hospital Universitário Cassiano Antonio de Moraes, Av. Marechal Campos, 1468, Maruípe, Vitória, ES CEP: 29075-910, Brazil. ${ }^{13}$ Disciplina de Reumatologia, Universidade Federal de Minas Gerais, Av. Pres. Antônio Carlos, 6627, Pampulha, Belo Horizonte, MG CEP: 31270-901, Brazil. ${ }^{14}$ Serviço de Reumatologia da Santa Casa de São Paulo, R. Dr. Cesário Mota Júnior, 112, Vila Buarque, São Paulo, SP CEP: 01221-020, Brazil. ${ }^{15}$ Hospital das Clínicas da Faculdade de Medicina de Ribeirão Preto (HCFMRP-USP), Av. Bandeirantes, 3900, Vila Monte Alegre, Ribeirão Preto, SP CEP: 14049-900, Brazil. ${ }^{16}$ Departamento de Educação Integrada em Saúde, Universidade Federal do Espírito Santo (UFES), Av. Marechal Campos, 1468, Maruípe, Vitória, ES CEP: 29040-090, Brazil.

${ }^{17}$ Universidade Federal do Espírito Santo, Serviço de Reumatologia, Hospital Universitário Cassiano Antônio de Moraes, Av. Marechal Campos, 1468, Maruípe, Vitória, ES CEP: 29075-910, Brazil. 
Received: 15 June 2019 Accepted: 26 November 2019 Published online: 18 December 2019

\section{References}

1. Moutsopoulos HM, Chused TM, Mann DL, Klippel JH, Fauci AS, Frank MM, et al. Sjögren's syndrome (sicca syndrome): current issues. Ann Intern Med. 1980;92:212-26.

2. Vitali C, Bombardieri S, Jonsson R, Moutsopoulos HM, Alexander EL, Carsons SE, et al. Classification criteria for Sjögren's syndrome: a revised version of the European criteria proposed by the American-European consensus group. Ann Rheum Dis. 2002:61:554-8.

3. Shiboski SC, Shiboski CH, Criswell LA, Baer AN, Challacombe S, Lanfranchi H, et al. American College of Rheumatology classification criteria for Sjögren's syndrome: a data-driven, expert consensus approach in the SICCA cohort. Arthritis Care Res (Hoboken). 2012;64(4):475-87.

4. Shiboski CH, Shiboski SC, Seror R, International Sjögren's Syndrome Criteria Working Group, et al. 2016 American College of Rheumatology/European League Against Rheumatism classification criteria for primary Sjögren's syndrome: a consensus and data-driven methodology involving three international patient cohorts. Ann Rheum Dis. 2017;76:9-16.

5. Higgins JPT, Green S, editors. Cochrane handbook for systematic reviews of interventions version 5.1.0 [updated March 2011]: The Cochrane Collaboration; 2011. Available from www.cochrane-handbook.org

6. Whiting PF, Rutjes AW, Westwood ME, Mallett S, Deeks JJ, Reitsma JB, et al, QUADAS-2: a revised tool for the quality assessment of diagnostic accuracy studies. Ann Intern Med. 2011:155(8):529-36.

7. Billings M, Dye BA, lafolla T, Baer AN, Grisius M, Alevizos I. Significance and implications of patient-reported Xerostomia in Sjögren's syndrome: findings from the National Institutes of Health Cohort. EBioMedicine. 2016;12:270-9.

8. Scully C, Georgakopoulou EA. Oral involvement. In: Ramos-Casals M, Stone $\mathrm{JH}$, Moutsopoulos HM, editors. Sjögren's syndrome. Diagnosis and therapeutics. London: Springer-Verlag; 2012. p. 85-106.

9. Falcão DP, Mota MH, Pires AL, Bezerra AC. Sialometria: aspectos de interesse clínico. Rev Bras Reumatol. 2013;53(6):525-31.

10. Pennec $Y L$, Letoux G, Leroy JP, Youinou P. Reappraisal of tests for xerostomia. Clin Exp Rheumatol. 1993;11(5):523-8.

11. Vitali C, Bombardieri S, Moutsopoulus HM, et al. Preliminary criteria for the classification of Sjögren' syndrome. Results of a prospective concerted action supported by the European community. Arthritis Rheum. 1993;36: 340-7.

12. Bookman AAM, Shen $\mathrm{H}$, Cook RJ, et al. Whole stimulated salivary flow. Arthritis Rheum. 2011;7:2014-20.

13. Rubin $\mathrm{P}$, Holt J. Secretory sialography in diseases of the major salivary glands. Am J Roentgenol Radium Therapy, Nucl Med. 1957;77:575-98.

14. Salerno S, Cannizzaro F, Lo Casto A. Letter to the editor: late allergic reaction following sialography. Dentomaxillofac Radiol. 2002;31:154.

15. Cockrell DJ, Rout P. Adverse reactions following sialography. Dentomaxillofac Radiol. 1993:22:41-2.

16. Obinata K, Sato T, Ohmori K, Shindo M, Nakamura M. A comparison of diagnostic tools for Sjogren syndrome, with emphasis on sialography, histopathology and ultrasonography. Oral Surg Oral Med Oral Pathol Oral Radiol Endod. 2010;109:129-34.

17. Poul JH, Brown JE, Davies J. Retrospective study of the effectiveness of high-resolution ultrasound compared with sialography in the diagnosis of Sjogren's syndrome. Dentomaxillofac Radiol. 2008;37(7):392-7.

18. Salaffi F, Carotti M, lagnocco A, Luccioli F, Ramonda R, Sabatini E, De Nicola M, Maggi M, Priori R, Valesini G, Gerli R, Punzi L, Giuseppetti GM, Salvolini U, Grassi W. Ultrasonography of salivary glands in primary Sjögren's syndrome: a comparison with contrast sialography and scintigraphy. Rheumatology (Oxford). 2008:47:1244-9.

19. Yonetsu K, Takagi Y, Sumi M, Nakamura T, Eguchi. Sonography as a replacement for sialography for the diagnosis of salivary glands affected by Sjögren's syndrome. Ann Rheum Dis. 2002;61:276-86.

20. Yoshiura K, Yuasa K, Tabata O, Araki K, Yonetsu K, Nakayama E, Kanda S, Shinohara M, Higuchi Y. Reliability of ultrasonography and sialography in the diagnosis of Sjogren's syndrome. Oral Surg Oral Med Oral Pathol Oral Radiol Endod. 1997;83:400-7.

21. Takagi Y, Kimura Y, Nakamura H, Sasaki M, Eguchi K, Nakamura T. Salivary gland ultrasonography: can it be an alternative to sialography as an imaging modality for Sjögren's syndrome? Ann Rheum Dis. 2010;69:1321-4.
22. Vitali C, Moutsopoulos HM, Bombardieri S, et al. (The European Study Group on Diagnostic Criteria for Sjogren's Syndrome). The European community study group on diagnostic critera for Sjögren'ss syndrome. Sensitivity and specificity of tests for ocular and oral involvement in Sjögren's syndrome. Ann Rheum Dis. 1994;53:637-47.

23. Wouter W, Kalk I, Vissink A, Spijkervet FKL, Bootsma H, Kallenberg CGM, Roodenburg JLN. Parotid sialography for diagnosing Sjogren syndrome. Oral Surg Oral Med Oral Pathol Oral Radiol Endod. 2002;94:131-7.

24. Lomas DJ, Carroll NR, Johnson G, Antoun NM, Freer CE. MR sialography. Work in progress. Radiology. 1996;200:129-33.

25. Niemelä RK, Takalo R, Pääkkö E, Suramo I, Päivänsalo M, Salo T, Hakala M. Ultrasonography of salivary glands in primary Sjogren's syndrome. A comparison with magnetic resonance imaging and magnetic resonance sialography of parotid glands. Rheumatology (Oxford). 2004;43:875-9.

26. Yu CQ, Zheng LY, Zhang J. The value of MRS in diagnosis of Sjögren's syndrome in parotid gland. Shanghai Kou Qiang Yi Xue. 2007;16:247-50.

27. Ohbayashi N, Yamada I, Yoshino N, Sasaki T. Sjögren syndrome: comparison of assessments with MR sialography and conventional sialography. Radiology. 1998;209:683-8.

28. Tonami H, Higashi K, Matoba M, Yokota H, Yamamoto I, Sugai S. A comparative study between MR sialography and salivary gland scintigraphy in the diagnosis of Sjögren syndrome. J Comput Assist Tomogr. 2001;25:262-8.

29. Kojima I, Sakamoto M, likubo M, Kumamoto H, Muroi A, Sugawara Y, SatohKuriwada S, Sasano T. Diagnostic performance of MR imaging of three major salivary glands for Sjögren's syndrome. Oral Dis. 2017;23(1):84-90.

30. Ramos-Casals M, Brito-zerón P, Prez-De-Lis M, et al. Clinical and prognostic significance of parotid scintigraphy in 405 patients with primary Sjogren's syndrome. J Rheumatol. 2010;37:585-90.

31. Schall GL, Anderson LG, Wolf RO, Herdt JR, Tarpley TM Jr, Cummings NA, et al. Xerostomia in Sjögren's syndrome. Evaluation by sequential salivary scintigraphy. JAMA. 1971;216:2109-16.

32. Milic VD, Petrovic RR, Boricic IV, Marinkovic-Eric J, Radunovic GL, Jeremic PD, et al. Diagnostic value of salivary gland ultrasonographic scoring system in primary Sjögren's syndrome: a comparison with scintigraphy and biopsy. J Rheumatol. 2009;36(7):1495-500.

33. Milic VD, Petrovic RR, Boricic IV, Marinkovic-Eric J, Radunovic GL, Jeremic PD, Pejnovic NN, Damjanov NS. Ultrasonography of major salivary glands could be an alternative tool to sialoscintigraphy in the American European classification criteria for primary Sjogren's syndrome. Rheumatology (Oxford). 2012:51:1081-5

34. De Vita S, Lorenzon G, Rossi G, Sabella M, Fossaluzza V. Salivary gland echography in primary and secondary Sjögren's syndrome. Clin Exp Rheumatol. 1992:10(4):351-6.

35. Takagi $Y$, Sumi M, Nakamura H, Iwamoto N, Horai Y, Kawakami A, et al. Ultrasonography as an additional item in the American College of Rheumatology classification of Sjögren's syndrome. Rheumatology (Oxford). 2014:53(11):1977-83.

36. Cornec D, Jousse-Joulin S, Marhadour T, Pers JO, Boisrame-Gastrin S, Renaudineau Y, et al. Salivary gland ultrasonography improves the diagnostic performance of the 2012 American College of Rheumatology classification criteria for Sjögren's syndrome. Rheumatology (Oxford). 2014. 53(9):1604-7.

37. Le Goff M, Cornec D, Jousse-Joulin S, Guellec D, Costa S, Marhadour T, Le Berre R, Genestet S, Cochener B, Boisrame-Gastrin S, Renaudineau Y, Pers JO, Saraux A, Devauchelle-Pensec V. Comparison of 2002 AECG and 2016 ACR/ EULAR classification criteria and added value of salivary gland ultrasonography in a patient cohort with suspected primary Sjögren's syndrome. Arthritis Res Ther. 2017;19(1):269.

38. Milic VD, Petrovic RR, Boricic IV, Radunovic GL, Pejnovic NN, Soldatovic I, et al. Major salivary gland sonography in Sjögren's syndrome: diagnostic value of a novel ultrasonography score (0-12) for parenchymal inhomogeneity. Scand J Rheumatol. 2010;39(2):160-6.

39. Jousse-Joulin S, Milic V, Jonsson MV, Plagou A, Theander E, Luciano N, et al. Is salivary gland ultrasonography a useful tool in Sjögren's syndrome? A systematic review. Rheumatology (Oxford). 2016;55(5):789-800.

40. Delli K, Dijkstra PU, Stel AJ, Bootsma H, Vissink A, Spijkervet FK. Diagnostic properties of ultrasound of major salivary glands in Sjögren's syndrome: a meta-analysis. Oral Dis. 2015:21(6):792-800.

41. Baldini C, Luciano N, Tarantini G, Pascale R, Sernissi F, Mosca M, et al. Salivary gland ultrasonography: a highly specific tool for the early diagnosis of primary Sjögren's syndrome. Arthritis Res Ther. 2015;17:146. 
42. Hocevar A, Ambrozic A, Rozman B, Kveder T, Tomsic M. Ultrasonographic changes of major salivary glands in primary Sjögren's syndrome. Diagnostic value of a novel scoring system. Rheumatology (Oxford). 2005;44(6):768-72.

43. Jousse-Joulin S, D'Agostino MA, Nicolas C, et al. Video clip assessment of a salivary gland ultrasound scoring system in Sjögren's syndrome using consensual definitions: an OMERACT ultrasound working group reliability exercise. Ann Rheum Dis. 2019;78:967-73.

44. Cornec D, Jousse-Joulin S, Pers JO, Marhadour T, Cochener B, BoisrameGastrin S, et al. Contribution of salivary gland ultrasonography to the diagnosis of Sjögren's syndrome: toward new diagnostic criteria? Arthritis Rheum. 2013;65(1):216-25.

45. Theander E, Mandl T. Primary Sjögren's syndrome: the diagnostic and prognostic value of salivary gland ultrasonography using a simplified scoring system. Arthritis Care Res (Hoboken). 2014;66(7):1102-7.

46. Hammenfors DS, Brun JG, Jonsson R, Jonsson MV. Diagnostic utility of major salivary gland ultrasonography in primary Sjögren's syndrome. Clin Exp Rheumatol. 2015;33(1):56-62.

47. Valim V, Hammenfors D, Jonsson MV. A ultrassonografia de glândula salivar na síndrome de Sjögren: alterações nas escalas cinza e semiquantitativa. In: Mendonça JA, editor. Fundamentos em Ultrassonografia na Reumatologia: uma abordagem na prática clínica. Rio de Janeiro: Elsevier; 2017.

48. Jousse-Joulin S, Nowak E, Cornec D, Brown J, Carr A, Carotti M, Fisher B, Fradin J, Hocevar A, Jonsson MV, Luciano N, Milic V, Rout J, Theander E, Stel A, Bootsma H, Vissink A, Baldini C, Baer A, Ng WF, Bowman S, Alavi Z, Saraux A, Devauchelle-Pensec V. Salivary gland ultrasound abnormalities in primary Sjögren's syndrome: consensual US-SG core items definition and reliability. RMD Open. 2017;3(1):e000364.

49. Fidelix T, Czapkowski A, Azjen S, Andriolo A, Trevisani VFM. Salivary gland ultrasonography as a predictor of clinical activity in Sjögren's syndrome. PLoS One. 2017;12(8):e0182287. https://doi.org/10.1371/journal.pone.0182287.

50. Seror R, Gottenberg JE, Devauchelle-Pensec V, Dubost JJ, Le Guern V, Hayem G, et al. European League Against Rheumatism Sjögren's syndrome disease activity index and European League Against Rheumatism Sjögren's syndrome patient-reported index: a complete picture of primary Sjögren's syndrome patients. Arthritis Care Res (Hoboken). 2013;65:1358-64.

51. Whitcher JP, Shiboski CH, Shiboski SC, et al. A simplified quantitative method for assessing KeratoconjunctivitisSicca from the Sjögren's syndrome international registry. Am J Ophthalmol. 2010;149(3):405-15.

52. Brito-Zerón $P$, Theander $E$, Baldini $C$, et al. Early diagnosis of primary Sjögren's syndrome: EULAR-SS task force clinical recommendations. Expert Rev Clinlmmunol. 2016;12(2):137-56.

53. Rischmueller M, Tieu J, Lester S. Primary Sjögren's syndrome. Best Pract Res Clin Rheumatol. 2016;30(1):189-220.

54. Zeev MS, Miller DD, Latkany R. Diagnosis od dry eye disease and emerging technologies. Clin Ophthalmol. 2014;2:581-90.

55. Barboza MN, Barbozy GN, de Melo GM, et al. Correlation between signals and symptoms of dry eye in Sjögren's syndrome patients. Arq Bras Oftalmol. 2008;71:547-52.

56. Adatia FA, Michaeli-Cohen A, Naor J, et al. Correlation between corneal sensitivity, subjective dry eye symptoms and corneal staining in Sjogren's syndrome. Can J Ophthalmol. 2004;39:767-71.

57. Wolffsohn JS, et al. TFOS DEWS II diagnostic methodology report. Ocul Surf. 2017;15(3):539-74

58. Oden NL, Lilienfeld DE, Lemp MA, et al. Sensitivity and specificity of a screening questionnaire for dry eye. Adv Exp Med Biol. 1998;438:807-20.

59. Bowman SJ, Booth DA, Platts RG, et al. Validation of the sicca symptoms inventory for clinical studies of Sjögren's syndrome. J Rheumatol. 2003;30: 1259-66.

60. Camp A, Wellik SR, Tzu JH, Feuer W, Arheart Kl, Sastry A, et al. Dry eye specific quality of life in veterans using glaucoma drops. Cont Les Anterior Eye. 2015;38:220-5

61. Schiffman RM, Christianson MD, Jacobsen $G$, et al. Reability and validity of the ocular surface disease index. Arch Ophthalmol. 2000;118(5):615-21.

62. Versura $P$, Frigato $M$, Cellini $M$, et al. Diagnostic performance of tear function tests in Sjögren's syndrome patients. Eye (Lond). 2007;21(2):229-37.

63. Foulks GN. Challenges and pitfalls in clinical trials of treatments for dry eye. Ocul Surf. 2003;1:20-30.

64. Valim V, Trevisani VF, de Sousa JM, et al. Current approach to dry eye disease. Clin Ver Allergy Immunol. 2015;49(3):288-97.

65. Mengher LS, Pandher KS, Bron AJ. Non-invasive tear film break-up time: sensitivity and specificity. Acta Ophthalmol. 1986;64(4):441-4.
66. Caffery B, Simpson T, Wang S, et al. Rose Bengal staining of the temporal conjunctiva differentiates Sjögren's syndrome from keratoconjunctivitis ssicca. Invest Ophthalmol Vis Sci. 2010;51:2381-7.

67. Rose-Nussbaumer J, Lietman TM, Shiboski CH, et al. Inter-grader agreement of the ocular staining score in the Sjögren's Internation Clinical Collaborative Alliance (SICCA) registry. Am J Ophthalmol. 2015;160(6):1150-3.

68. VanBijsterveld OP. Diagnostic testes in the sicca syndrome. Arch Ophthalmol. 1969:82:10-4

69. Routsias JG, Tzioufas AG. Sjögren's syndrome - study of autoantigens and autoantibodies. Clinic Rev Allerg Immunol. 2007;32:238-51.

70. Fayyaz A, Kurien BT, Scofield RH. Autoantibodies in Sjögren's syndrome. Rheum Dis Clin N Am. 2016:42:419-34.

71. Harley JB, Alexander EL, Bias WB, Fox OF, Provost TT, Reichlin M, et al. AntiRo (SS-A) and anti-La (SS-B) in patients with Sjögren's syndrome. Arthritis Rheum. 1986:29:196-206.

72. Aggarwal A. Role of autoantibody testing. Best Pract Res Clin Rheumatol. 2014;28:907-20.

73. Agmon-Levin N, Dagan A, Peri Y, Anaya JM, Selmi C, Tincani A, et al. The interaction between anti-Ro/SSA and anti-La/SSB autoantibodies and antiinfectious antibodies in a wide spectrum of auto-immune diseases: another angle of the autoimmune mosaic. Clin Exp Rheumatol. 2017;35:929-35.

74. Baer AN, McAdams DeMarco M, Shiboski SC, Shiboski SC, Lam MY, Challacombe S, et al. The SSB-positive/SSA-negative antibody profile is not associated with key phenotypic features of Sjögren's syndrome. Ann Rheum Dis. 2015;74:1557-61.

75. Brito-Zerón P, Acar-Denizli N, Ng F, et al. How immunological profile drives clinical phenotype of primary Sjögren's syndrome at diagnosis: analysis of 10,500 patients (Sjögren Big Data Project). Clin Exp Rheumatol. 2018;36 Suppl 112(3):102-12.

76. Alexander EL, Ranzenbach MR, Kumar AJ, Kozachuk WE, Rosenbaum AE, Patronas N, Harley JB, Reichlin M. Anti-Ro(SS-A) autoantibodies in central nervous system disease associated with Sjögren's syndrome (CNS-SS): clinical, neuroimaging, and angiographic correlates. Neurology. 1994;44(5): 899-908.

77. Rivera TL, Izmirly PM, Birnbaum BK, et al. Disease progression in mothers of children enrolled in the research registry for neonatal lupus. Ann Rheum Dis. 2009;68:828-35

78. Theander E, Jonsson R, Sjöström B, Brokstad K, Olsson P, Henriksson G. Prediction of Sjögren's syndrome years before diagnosis and identification of patients with early onset and severe disease course by autoantibody profiling. Arthritis Rheum. 2015;67:2427-36.

79. Franceschini F, Cavazzana I. Anti-Ro/SSA and La/SSB antibodies. Autoimmunity. 2005;38:55-63.

80. Lee AYS. A review of the role and clinical utility of anti-Ro52/TRIM21 in systemic autoimmunity. Rheumatol Int. 2017;37:1323-33.

81. Bloch DB. The anti-Ro/SSA and anti-La/SSB antigen-antibody systems. Available from: https://www.uptodate.com/contents/the-anti-ro-ssa-andanti-la-ssb-antigen-antibody-systems. Literature review current through: Aug 2017. This topic last updated: Feb 21, 2017.

82. Menor Almagro R, Jurado Roger A, Rodríguez Gutiérrez FJ, Solís Díaz R, Cardiel MH, Salaberri Maestrojuan JJ. Association of anti-Ro52, anti-Ro60 and anti-La antibodies with diagnostic, clinical and laboratory features in a referral hospital in Jerez, Spain. Reumatol Clin. 2016:12:256-62.

83. Varela-Centelles P, Seoane-Romero JM, Sánchez-Sánchez M, GonzálezMosquera A, Diz-Dios P, Seoane J. Minor salivary gland biopsy in Sjögren's syndrome: a review and introduction of a new tool to ease the procedure. Med Oral Patol Oral Cir Bucal. 2014;19(1):e20-3.

84. Guellec D, Cornec D, Jousse-Joulin S, Marhadour T, Marcorelles P, Pers JO, Saraux A, Devauchelle-Pensec V. Diagnostic value of labial minor salivary gland biopsy for Sjögren's syndrome: a systematic review. Autoimmun Rev. 2013;12(3):416-20.

85. Fisher BA, Jonsson R, Daniels T, et al. Sjögren's histopathology workshop group (appendix) from ESSENTIAL (EULAR Sjögren's syndromestudygroup). Standardisation of labial salivary gland histopathology in clinical trials in primary Sjögren's syndrome. Ann Rheum Dis. 2017;76(7):1161-8.

86. Giovelli RA, Santos MC, Serrano ÉV, Valim V. Clinical characteristics and biopsy accuracy in suspected cases of Sjögren's syndrome referred to labial salivary gland biopsy. BMC Musculoskelet Disord. 2015;16:30. https://doi.org/ 10.1186/s12891-015-0482-9.

87. Chisholm DM, Mason DK Labial salivary gland biopsy in Sjögren's disease J Clin Pathol. 1968;21(5):656-60. 
88. Greenspan JS, Daniels TE, Talal N, Sylvester RA. The histopathology of Sjögren's syndrome in labial salivary gland biopsies. Oral Surg Oral Med Oral Pathol. 1974;37(2):217-29.

89. Daniels TE, Silverman S Jr, Michalski JP, Greenspan JS, Sylvester RA, Talal N. The oral component of Sjögren's syndrome. Oral Surg Oral Med Oral Pathol. 1975;39(6):875-85.

90. Baldini C, Talarico R, Tzioufas AG, Bombardieri S. Classification criteria for Sjogren's syndrome: a critical review. J Autoimmun. 2012;39(1-2):9-14

91. Sjögren's International Collaborative Clinical Alliance (SICCA). Avaiable from: https://sicca-online.ucsfedu

92. Daniels TE, Cox D, Shiboski CH, Schiødt M, Wu A, Lanfranchi H, Umehara H, Zhao Y, Challacombe S, Lam MY, De Souza Y, Schiødt J, Holm H, Bisio PA, Gandolfo MS, Sawaki T, Li M, Zhang W, Varghese-Jacob B, Ibsen P, Keszler A, Kurose N, Nojima T, Odell E, Criswell LA, Jordan R, Greenspan JS, Sjögren's International Collaborative Clinical Alliance Research Groups. Associations between salivary gland histopathologic diagnoses and phenotypic features of Sjögren's syndrome among 1,726 registry participants. Arthritis Rheum. 2011;63(7):2021-30.

93. Risselada AP, Hair M, Kruize AA, Bijlsma JW, van Roon JA. Lymphocytic focus score as a prognostic tool. Ann Rheum Dis. 2015;74(4):e31.

94. Risselada AP, Kruize AA, Goldschmeding R, Lafeber FP, Bijlsma JW, van Roon JA. The prognostic value of routinely performed minor salivary gland assessments in primary Sjögren's syndrome. Ann Rheum Dis. 2014;73(8):1537-40.

95. Haacke EA, van der Vegt B, Vissink A, Spijkervet FKL, Bootsma H, Kroese FGM. Standardisation of the detection of germinal centres in salivary gland biopsies of patients with primary Sjögren's syndrome is needed to assess their clinical relevance. Ann Rheum Dis. 2018;77(6):e32. https://doi.org/10. 1136/annrheumdis-2017-212164.

96. Jonsson MV, Skarstein K. Follicular dendritic cells confirm lymphoid organization in theminor salivary glands of primary Sjögren's syndrome. J Oral Pathol Med. 2008;37(9):515.

97. Theander E, Vasaitis L, Baecklund E, Nordmark G, Warfvinge G, Liedholm R, Brokstad K, Jonsson R, Jonsson MV. Lymphoid organisation in labial salivary gland biopsies is a possible predictor for the development of malignant lymphoma in primary Sjögren's syndrome. Ann Rheum Dis. 2011;70(8):1363-8.

98. Sène $D$, et al. Ectopic germinal center-like structures in minor salivary gland biopsy tissue predict lymphoma occurrence in patients with primary Sjögren's syndrome. Arthritis Rheumatol. 2018;70(9):1481-8.

99. Barone F, Campos J, Bowman S, Fisher BA. The value of histopathological examination of salivary gland biopsies in diagnosis, prognosis and treatment of Sjögren's syndrome. Swiss Med Wkly. 2015;145:w14168.

100. Campos J, Hillen MR, Barone F. Salivary gland pathology in Sjögren's syndrome. Rheum Dis Clin N Am. 2016;42(3):473-83.

\section{Publisher's Note}

Springer Nature remains neutral with regard to jurisdictional claims in published maps and institutional affiliations.

Ready to submit your research? Choose BMC and benefit from:

- fast, convenient online submission

- thorough peer review by experienced researchers in your field

- rapid publication on acceptance

- support for research data, including large and complex data types

- gold Open Access which fosters wider collaboration and increased citations

- maximum visibility for your research: over $100 \mathrm{M}$ website views per year

At $\mathrm{BMC}$, research is always in progress.

Learn more biomedcentral.com/submissions 